This item was submitted to Loughborough's Research Repository by the author.

Items in Figshare are protected by copyright, with all rights reserved, unless otherwise indicated.

\title{
Analysis of ferrite formed in 321 grade austenitic stainless steel
}

PLEASE CITE THE PUBLISHED VERSION

http://dx.doi.org/10.1179/1743284714Y.0000000564

\section{PUBLISHER}

Maney Publishing / @ Institute of Materials, Minerals and Mining

VERSION

AM (Accepted Manuscript)

\section{PUBLISHER STATEMENT}

This work is made available according to the conditions of the Creative Commons Attribution-NonCommercialNoDerivatives 4.0 International (CC BY-NC-ND 4.0) licence. Full details of this licence are available at: https://creativecommons.org/licenses/by-nc-nd/4.0/

\section{LICENCE}

CC BY-NC-ND 4.0

\section{REPOSITORY RECORD}

Green, Graham, Rebecca L. Higginson, Simon C. Hogg, Sarah Spindler, Christopher Hamm, and J. Najorka. 2015. "Analysis of Ferrite Formed in 321 Grade Austenitic Stainless Steel". figshare.

https://hdl.handle.net/2134/18363. 


\title{
Analysis of Ferrite Formed in a 321 Grade Austenitic Stainless Steel
}

Authors: Graham Green ${ }^{1}$, Dr Rebecca Higginson ${ }^{1}$, Dr Simon Hogg ${ }^{1}$, Dr Sarah Spindler ${ }^{2}$ and Dr Chris Hamm²

${ }^{1}$ Department of Materials, Loughborough University, Loughborough, LE11 3TU, UK

${ }^{2}$ EDF Energy, Barnett Way, Barnwood, Gloucester, GL4 3RS, UK

Contact: G.Green@lboro.ac.uk

Keywords: Austenite, Ferrite, Solution heat treatment, Thermal Ageing

\begin{abstract}
A significant fraction of ferrite has been identified in a 321 grade austenitic stainless steel in the solution heat treated condition. The microstructures were analysed using EBSD, EDS and $\mathrm{XRD}$ and the stability of the ferrite investigated using heat treatments in a tube furnace, dilatometer and high temperature XRD. The ferrite dissolved around $800^{\circ} \mathrm{C}$ and then formed again on cooling at temperatures under $200^{\circ} \mathrm{C}$. Thermodynamic predictions showed a significant ferrite content at room temperature under equilibrium conditions and the DeLong diagrams predict an austenite + martensite microstructure in the cast condition. Sensitivity analysis on the DeLong diagram has shown that the nitrogen content had a large effect on the austenite stability. The low nitrogen content measured in the as-received material can be attributed to the instability of the austenite and its subsequent transformation to ferrite on cooling. It was found that thermal ageing of the material caused further transformation of austenite to ferrite as well as the formation of sigma phase that appears higher in nitrogen than the matrix phases. The diffusion of nitrogen into sigma phase may cause instability of the austenite which could cause further transformation of austenite to ferrite on cooling from the ageing temperature. The transformation of austenite to ferrite is known to be accompanied by an increase in volume which may be of relevance to components made with tight dimensional tolerances.
\end{abstract}

\section{Introduction}

Austenitic stainless steels are frequently used in energy generation applications where there is a requirement of maintaining mechanical properties, as well as corrosion and oxidation resistance at elevated temperatures for over 20 years [1]. Components made from austenitic stainless steels for use in the energy industry include steam conveyance tubing, heat 
exchangers and fuel plug guide units. Stabilised austenitic stainless steels, such as the 321 grades, can have additions of titanium which form titanium carbo-nitrides [2]. It is desirable to form carbides with an element such as titanium in place of chromium to prevent issues with sensitization, however the formation of these carbo-nitrides removes carbon and nitrogen from the solid solution as they precipitate, which can alter the stability of the steel.

After casting, stainless steels are given a solution heat treatment to dissolve any delta ferrite ( $\delta)$ that remains from solidification. The temperature and time of the solution heat treatment applied to the steel is dependent on the steel composition and the thickness of the components. The ASTM specification for a 321 grade austenitic stainless steel tube material states that a temperature of $1050^{\circ} \mathrm{C}$ for 1.5 hours should be sufficient [3] and modifications to the temperature and time should be made dependant on component dimensions. The aim of these solution heat treatments is to result in a fully austenitic matrix microstructure at room temperature, as the FCC crystal structure is desired for these high temperature applications. Due to the composition of austenitic stainless steels, specifically the carbon, nitrogen and nickel content, some delta ferrite can remain after a solution heat treatment.

There are other mechanisms that cause the transformation of austenite, for example, the martensitic transformation of austenite to two products, BCC $\left(\alpha^{\prime}\right)$ and $\mathrm{HCP}(\varepsilon)$ has been observed in $18 \% \mathrm{Cr}, 8 \% \mathrm{Ni}$ stainless steels. The formation of $\alpha^{\prime}$ is usually associated with deformation and it is known that martensite can form in the 300 series of stainless steel during deformation at temperatures well above the marteniste start temperature [4-7]. This effect can be induced by deformation and also by cooling to a low temperature $\left(-195^{\circ} \mathrm{C}\right)$ [8,9]. Recent work by the authors has reported that a 321 grade stainless steel contained ferrite in the solution heat treated condition and that the amount of ferrite increased with ageing [10]. The transformation of $\gamma$ to $\alpha$ or $\alpha^{\prime}$ is of industrial relevance when it is considered that a brittle/ductile transition could be introduced and an increase in volume is incurred which is generally quoted as $\sim 4 \%$ for a complete transformation [11]

Thermodynamic calculations are used to predict the stable phases in metals under equilibrium conditions. There are thermodynamic databases such as the TCFE database which have been specifically designed for predicting the stable phases formed in steels, and have successfully been used with titanium and niobium stabilised austenitic stainless steels [12]. The models take composition as the input, and can give an output of the mass fraction and chemical composition of phases under equilibrium conditions. It should be noted that the predictions at 
low temperatures may take thousands of years to reach for high alloy steels due to the low driving force for change. There are other ways of predicting microstructures of steels based on chemical composition, for instance DeLong and Schaeffler diagrams were produced by examining the microstructure of many steels with differing compositions and noting the effect on microstructure $[13,14]$. The $\mathrm{X}$ axis of the diagram is the chromium equivalent and the $\mathrm{Y}$ axis is the nickel equivalent, these equivalents respectively describe the strength of the ferrite and austenite stabilising elements. There are many versions of the equations used to calculate the chromium and nickel equivalents, the equations used in this paper are shown in Equations 1 and 2 [14].

$$
\begin{array}{lll}
\mathrm{CrEqv}=\mathrm{Cr}+\mathrm{Mo}+(1.5 \times \mathrm{Si})+(0.5 \times \mathrm{Nb}) & ------ & \text { Equation } 1 \\
\mathrm{NiEqv}=\mathrm{Ni}+(30 \times \mathrm{C})+(0.5 \times \mathrm{Mn})+(30 \times \mathrm{N}) & ------- & \text { Equation } 2
\end{array}
$$

The diagram is split into regions of phases that are likely to form after welding based upon a steels composition but are often used to predict the microstructures of cast steels as there are similarities to weld metals. Thermodynamic predictions along with other methods such as the DeLong diagram are useful tools when examining the behaviour of existing compositions and determine the sensitivity of certain elements, for example the effect of nitrogen content on austenite stability. The phase stability of the steel can be controlled by modifying the composition; for example the austenite stability is particularly sensitive to the elements, $\mathrm{N}, \mathrm{Cr}$, $\mathrm{Ni}$ and $\mathrm{C}$. Nitrogen and carbon have a strong effect on stabilising the austenite microstructure and with sufficient quantities can suppress the formation of low temperature ferrite and martensite with a greater effect than nickel [15].

This paper characterises the microstructures formed in a 321 grade stainless steel. Heat treatments have been applied using a number of techniques and their effect on the microstructures monitored and investigated.

\section{Experimental procedure}

The material was supplied as thin section tube with the composition shown in Table 1. The received material was cut into smaller samples, a sample was then mounted and prepared in the as-received condition to analyse the initial microstructure. Standard metallographic 
preparation techniques were used to prepare the samples, grinding through successively finer papers then polishing to $1 \mu \mathrm{m}$ with diamond suspensions before final polishing with a colloidal silica suspension.

Heat treatments were performed in a tube furnace, dilatometer, a differential scanning calorimeter (DSC) and in an X-ray diffractometer (XRD) with a high temperature chamber. A tube furnace was used to hold a sample of the metal at $1050^{\circ} \mathrm{C}$ for 90 minutes, the sample was then removed and cooled in air. A dilatometer was used as an accurate furnace as the sample had a thermocouple attached so the temperature could be recorded and compared against the temperature profile. The cooling rate of the sample was controlled using helium gas. Two heating profiles were used, the first was an isothermal hold of 90 minutes at $1200^{\circ} \mathrm{C}$ then cooling at $200^{\circ} \mathrm{Cmin}^{-1}$ to room temperature, the second was an isothermal hold at $1150^{\circ} \mathrm{C}$ for 10 minutes then cooling at $500^{\circ} \mathrm{Cs}^{-1}$ to room temperature. The DSC was used to raise the temperature of a small sample of the stainless steel to $1600^{\circ} \mathrm{C}$ at $50^{\circ} \mathrm{Cmin}-1$ then cooling to room temperature at the same rate. The DSC heat treatment was performed in a vacuum and in a nitrogen containing atmosphere.

A GeniX high flux X-ray system was used with a high temperature vacuum chamber for the XRD experiments. The area irradiated by the micro-source was approximately $5 \mathrm{~mm}$ by 230 microns. The operating conditions were $50 \mathrm{kV}$ and $1 \mathrm{~mA}$. The samples were prepared from the unaged 321 stainless steel and sectioned to be $10 \times 5 \mathrm{~mm}$ strips. These strips were ground then polished to a thickness of $100 \mu \mathrm{m}$, this was to make sure the samples would not experience a thermal gradient when rapidly heating and also to remove artefacts that may arise due to having a highly deformed surface. The sample was mounted onto a platinum strip with a thermocouple attached directly under the sample. The data was collected over 300 seconds during isothermal holds. The sample temperature was increased to $1000^{\circ} \mathrm{C}$ then cooled back down to room temperature.

The characterisation of the material was performed by using Electron Backscatter Diffraction (EBSD), Energy-dispersive X-ray Spectroscopy (EDS) and XRD data. Thermodynamic predictions were made using the Thermocalc software package with the TCFE 5 database for steels. The DeLong diagrams were digitized from diagrams [14] and imported into excel so the effect of varying the composition of the steel could be examined. 
Table 1: Composition of the as-received 321 stainless steel measured in wt.\% and the ASTM specification for a 321 tube [16]. The chemistry was measured by inductively coupled plasma optical emission spectroscopy (ICP-OES).

\begin{tabular}{|c|c|c|c|c|c|c|c|c|c|c|c|c|c|c|}
\hline $\begin{array}{c}\text { Element } \\
(\mathbf{w t . \%})\end{array}$ & $\mathbf{C}$ & $\mathbf{S i}$ & $\mathbf{M n}$ & $\mathbf{C r}$ & $\mathbf{M o}$ & $\mathbf{N i}$ & $\mathbf{T i}$ & $\mathbf{N}$ & $\mathbf{P}$ & $\mathbf{S}$ & $\mathbf{A l}$ & $\mathbf{V}$ & $\mathbf{N b}$ & $\mathbf{F e}$ \\
\hline $\begin{array}{c}\text { Measured } \\
\text { composition }\end{array}$ & 0.046 & 0.56 & 1.53 & 17.38 & 0.45 & 8.92 & 0.33 & 0.015 & 0.019 & 0.01 & 0.046 & 0.05 & 0.02 & Bal. \\
\hline ASTM Spec & 0.8 & 0.75 & 2 & $17-19$ & 0 & $9-12$ & 0.9 & 0.1 & 0.045 & 0.03 & 0 & 0 & 0 & Bal. \\
\hline
\end{tabular}

\section{Results and Discussion}

\section{Characterisation of the metal in the as-received condition}

An EBSD phase map of the as-received 321 grade stainless steel is shown in Figure 1 (a). The map shows that the material has both austenite and ferrite grains in approximately equal proportions. The austenite has an equiaxed grain structure and the ferrite an irregular morphology. The phase map shows that the ferrite formed with both needle morphology and idiomorphic morphology. Titanium carbo-nitrides were identified throughout the sample, one has been labelled on the phase map shown Figure 1 (a), this carbide has been indexed as austenite as they share the same crystal structure. The presence of large carbo-nitrides has the effect of removing austenite stabilising elements from the austenite. Figure 1 (b) shows the corresponding inverse pole figure map, it shows that the ferrite has transformed from the austenite as the orientation of the ferrite is dependent on the austenite grain in which it has formed. Figure 1 (c) shows a secondary electron image of a region that contain both austenite and ferrite grains. The line shown through the centre of the micrograph indicates the line that the EDS data was collected from. Figure 1 (d) shows the EDS line scan data, the result shows no significant chemical difference between the two phases when analysed using this technique. The chemical similarity between the two phases suggests that ferrite has formed displacively from the austenite.

There are a number of ferrite morphologies that can form in steels, delta ferrite can be ruled out as this is a phase that forms at high temperatures and is usually higher in chromium and lower in nickel than austenite when formed in high alloy steels such as this. Martensite shares some similarities with the ferrite observed in the as-received sample, and has previously been 
observed to form during deformation in a 321 grade stainless steel [4]. Unfortunately there is insufficient evidence at this stage to narrow the ferrite phase down to one particular subset and due to the inconsistent morphology of this phase has lead it to be identified with the blanket term 'ferrite'.
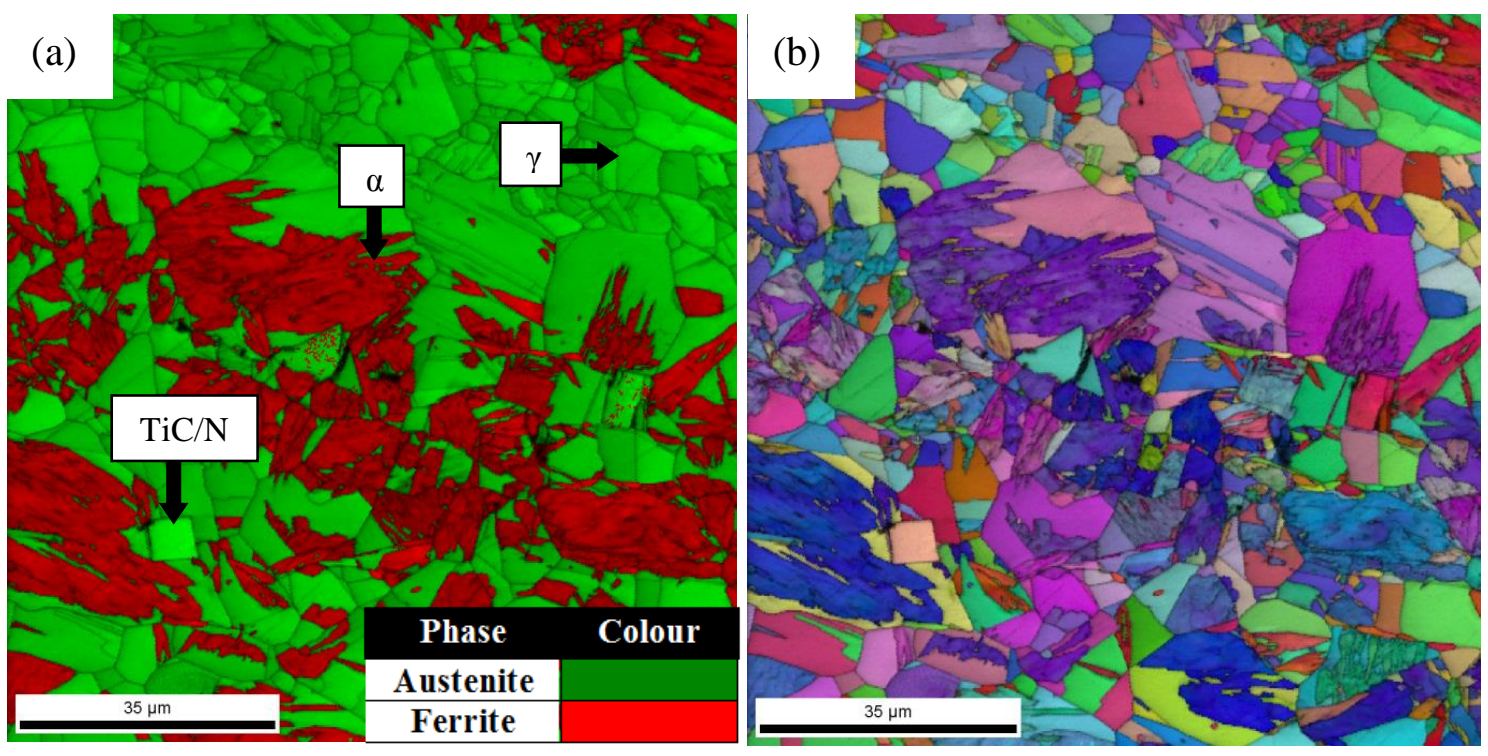

Figure 1: The EBSD phase map in shows (a) combined phase and image quality map constructed from EBSD data and (b) a combined inverse pole figure and image quality map of the as-received 321 stainless steel.

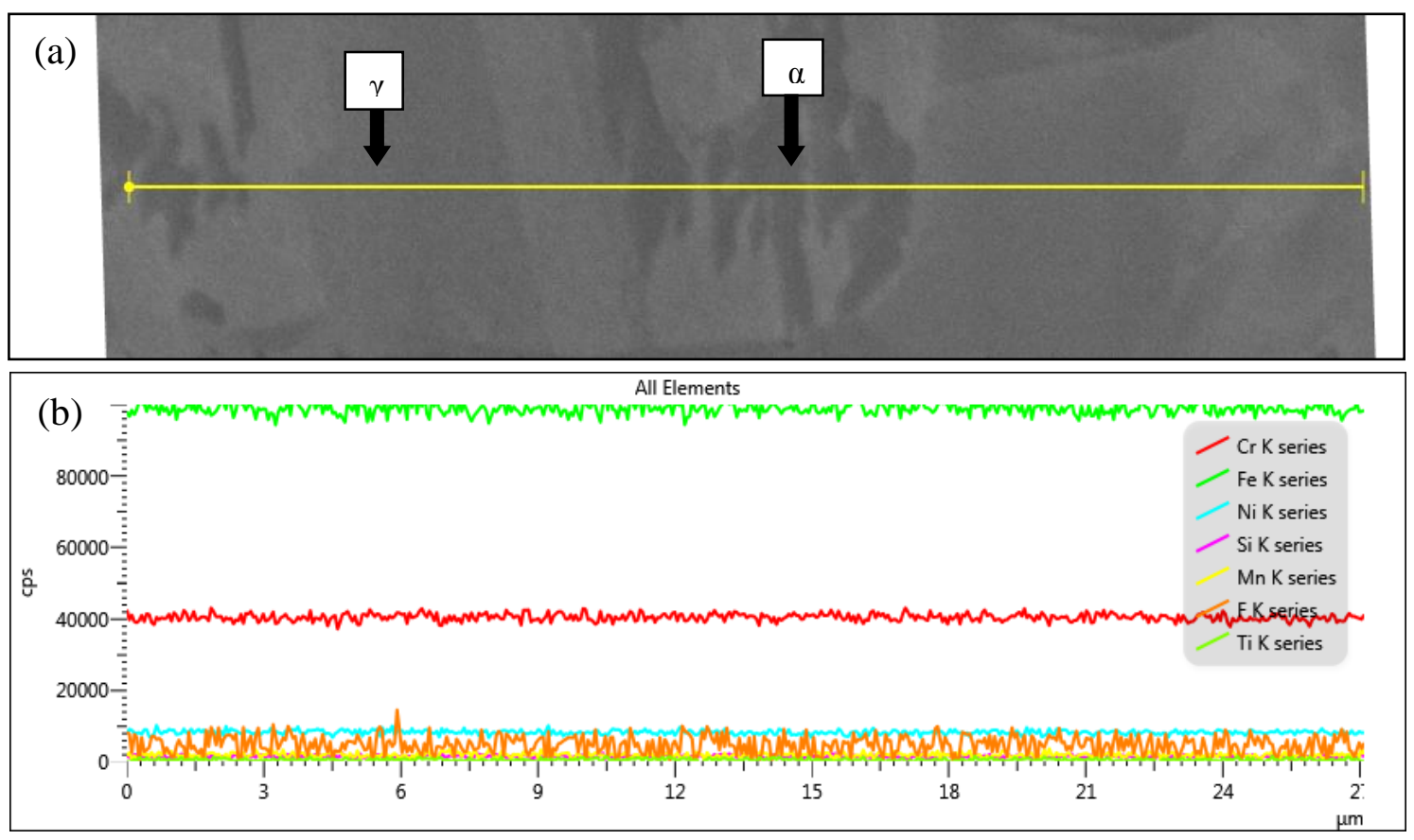

Figure 2: An EDS line scan through regions containing both ferrite and austenite matrix phases. The line shown in the secondary electron image in (a) designates the region where the EDS data (b) was collected from. 


\section{Application of various heating programs}

Ferrite/martensite phases studied in austenitic stainless steels are known to form during deformation and cooling to low temperatures, but as the exact history of the component was not known, solution heat treatments were applied to see if the formation of ferrite was reversible. Themocalc was used to predict the phases that are stable from room temperature up to the melting point of the steel. The result from the phase prediction shown in Figure 3 predicts that between $800^{\circ} \mathrm{C}$ and $1200^{\circ} \mathrm{C}$ the steel should be completely austenite. The heat treatments were designed with this in mind, as this also agrees with the standard industrial solution heat treatments from austenitic stainless steels which state a temperature of $1050^{\circ} \mathrm{C}$ applied for a time of 1.5 hours (adjusted for thickness) is sufficient to fully austenise the steel [3].

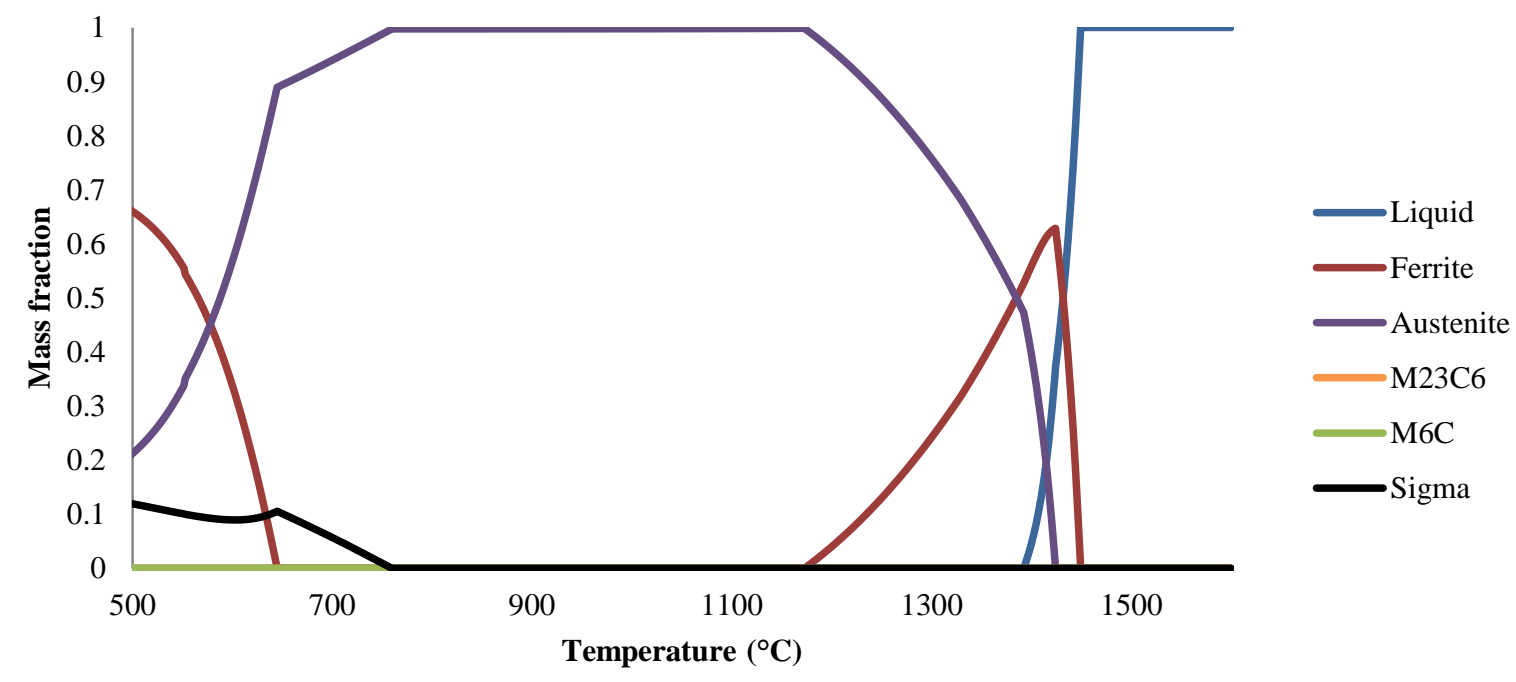

Figure 3: Phase prediction preformed in Thermocalc using the TCFE database. The chemical composition of the bulk 321 grade steel shown in Table 1 was used as the input for the model. The plot shows the major phases present between $500-1600^{\circ} \mathrm{C}$.

The result of an isothermal hold for 1.5 hours at $1050^{\circ} \mathrm{C}$ in an open tube furnace before cooling in air can be seen in the EBSD phase map Figure 4 (a). The morphology of the matrix phases closely resembles the microstructures found in the as-received materials. This suggested that either the temperature of the solution heat treatment was not high enough or the time not long enough. The EBSD phase map shown in Figure 4 (b) shows the result of a dilatometer experiment where the sample was held at $1200^{\circ} \mathrm{C}$ before being cooled at $50^{\circ} \mathrm{Cs}^{-1}$. The higher temperature resulted in grain growth but did not remove the ferrite, however the 
morphology of the ferrite was altered along with the austenite grains. Figure 5 shows a trace for another dilatometer experiment which held a sample at $1150^{\circ} \mathrm{C}$ for 10 minutes before cooling at a rate of $500^{\circ} \mathrm{Cs}^{-1}$. The cooling rate was selected as it was sufficiently fast to ensure that if the transformation was displacive, there would be very little diffusion involved. The dilatometer trace shows the change in length against the measured temperature, as the sample was heated it did not show a pronounced phase change as would be expected, this could be due to the ferrite dissolving over a large temperature range. During cooling there is a small indication that a phase change is occurring around $100^{\circ} \mathrm{C}$, a transformation at a low temperature is indicative of a displacive transformation. The sample showed a qualitatively higher magnetic response after the fast cool dilatometer experiment, which is indicative of an increased fraction of displacively formed ferrite.

The EBSD maps in Figure 4 (c) shows the sample after melting in a vacuum in a DSC then being rapidly cooled. It can be seen that the microstructure is almost entirely ferrite, with only a small amount of remaining austenite. The last phase map shown in Figure 4 (d) was collected from a sample that was melted and cooled in a DSC which had a nitrogen containing atmosphere, it shows that there is no remaining ferrite and large austenite grains. The data from the DSC has not been included as it showed no indication of the dissolution or the formation of ferrite. 

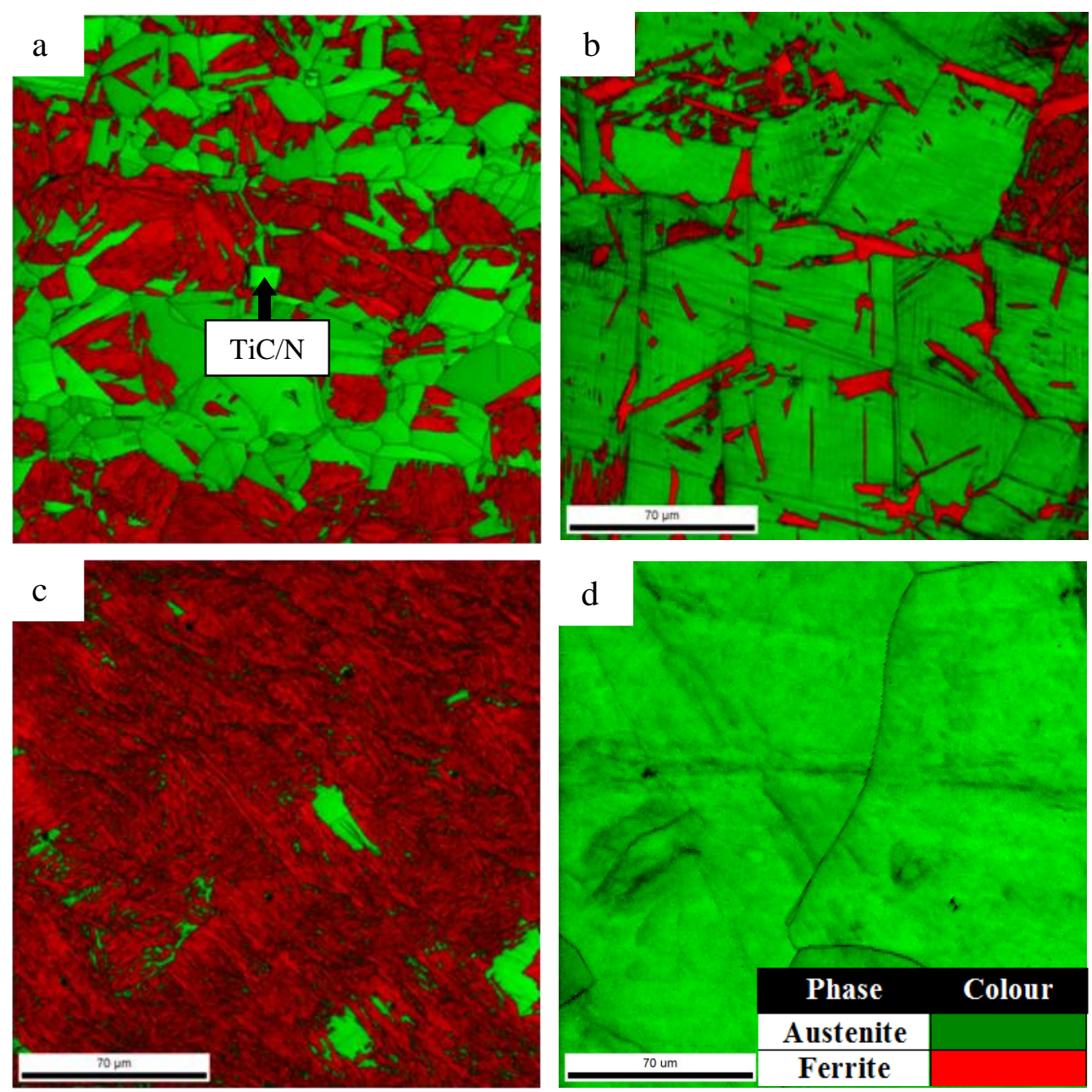

Figure 4: The EBSD phase maps show from various heat treatments on samples of the 321 steel (a) 90 minutes at $1050^{\circ} \mathrm{C}$ in an open tube furnace, (b) 90 minutes at $1200^{\circ} \mathrm{C}$ in a dilatometer, (c) melting a sample in a vacuum atmosphere and $(d)$ the sample melted and cooled in a nitrogen containing atmosphere .

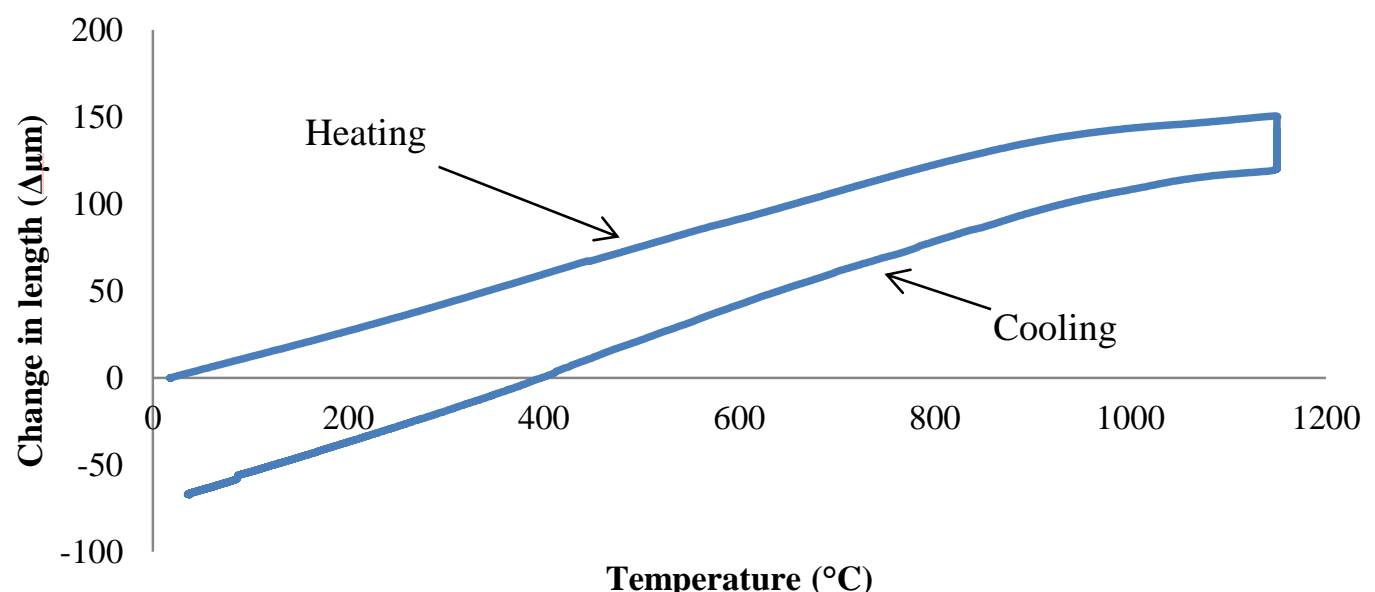

Figure 5: Dilatometer change in length against temperature for the sample heated at $100{ }^{\circ} \mathrm{Cs}^{-1}$, isothermally held at $1150^{\circ} \mathrm{C}$ for 10 minutes then cooled at $500^{\circ} \mathrm{Cs}^{-1}$. 
To further investigate what phases were present during heating and cooling from the solution heat treatment temperature, an XRD with a high temperature stage was used. Figure 6 (a) shows XRD data collected from a thin sample of the 321 metal in the unaged condition while at room temperature, austenite and ferrite were found to be present and the corresponding peaks in the $40^{\circ} 2 \theta$ region have been labelled. Figure 6 (b) shows the XRD data that was collected from the same sample while at $1050^{\circ} \mathrm{C}$ where it can be seen that the ferrite peak has been completely removed, this shows that the ferrite is dissolving at high temperature but the dilatometer was not sensitive enough to register the transformation. Figure 7 shows a series of XRD patterns collected at different temperatures and focused over a limited angle range which contain the strongest FCC and BCC peaks. The traces has been offset by an arbitrary amount and the background removed by baseline fitting so the change in peak intensities can be visually compared. The ferrite dissolved when heated to over $800^{\circ} \mathrm{C}$, this is identified by the reducing relative intensity of the ferrite peak. During cooling the ferrite formed again at temperatures below $200^{\circ} \mathrm{C}$. The transformation at low temperatures again suggests that it is a displacive transformation.
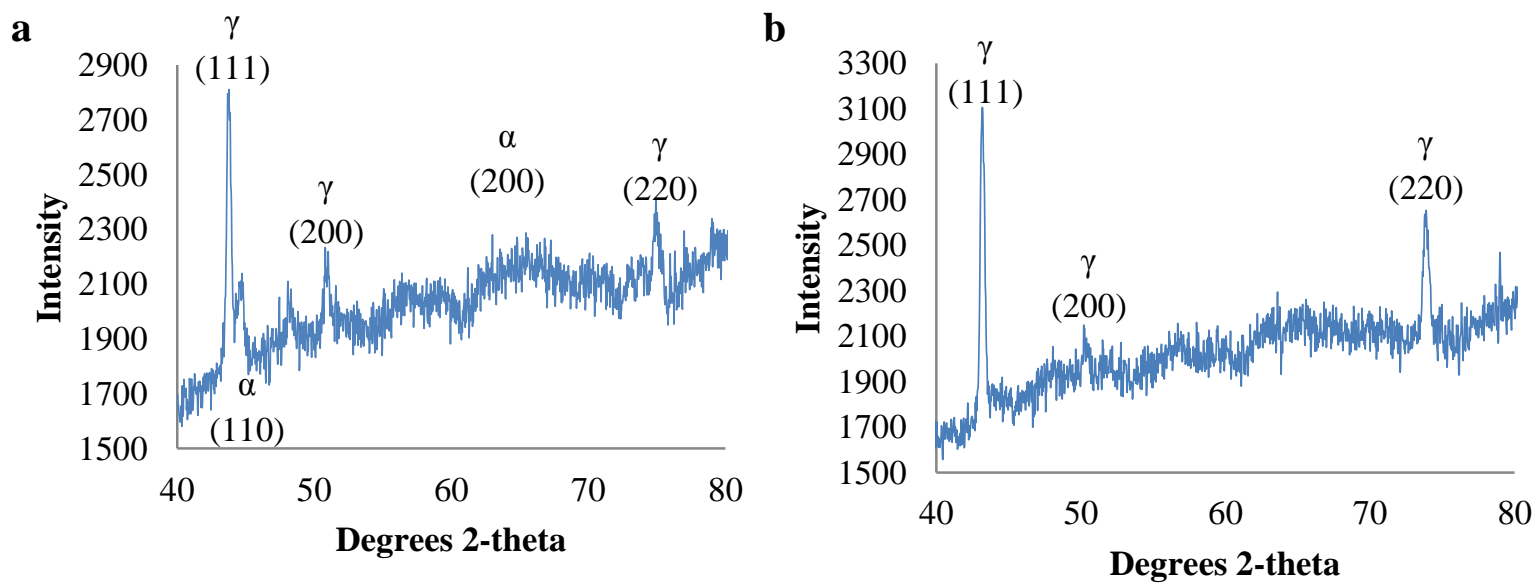

Figure 6: XRD traces collected from small samples of the unaged 321 metal at (a) room temperature and $(b) 1050^{\circ} \mathrm{C}$. The $\mathrm{FCC}$ and $\mathrm{BCC}$ peaks with the largest intensities have been labelled. 


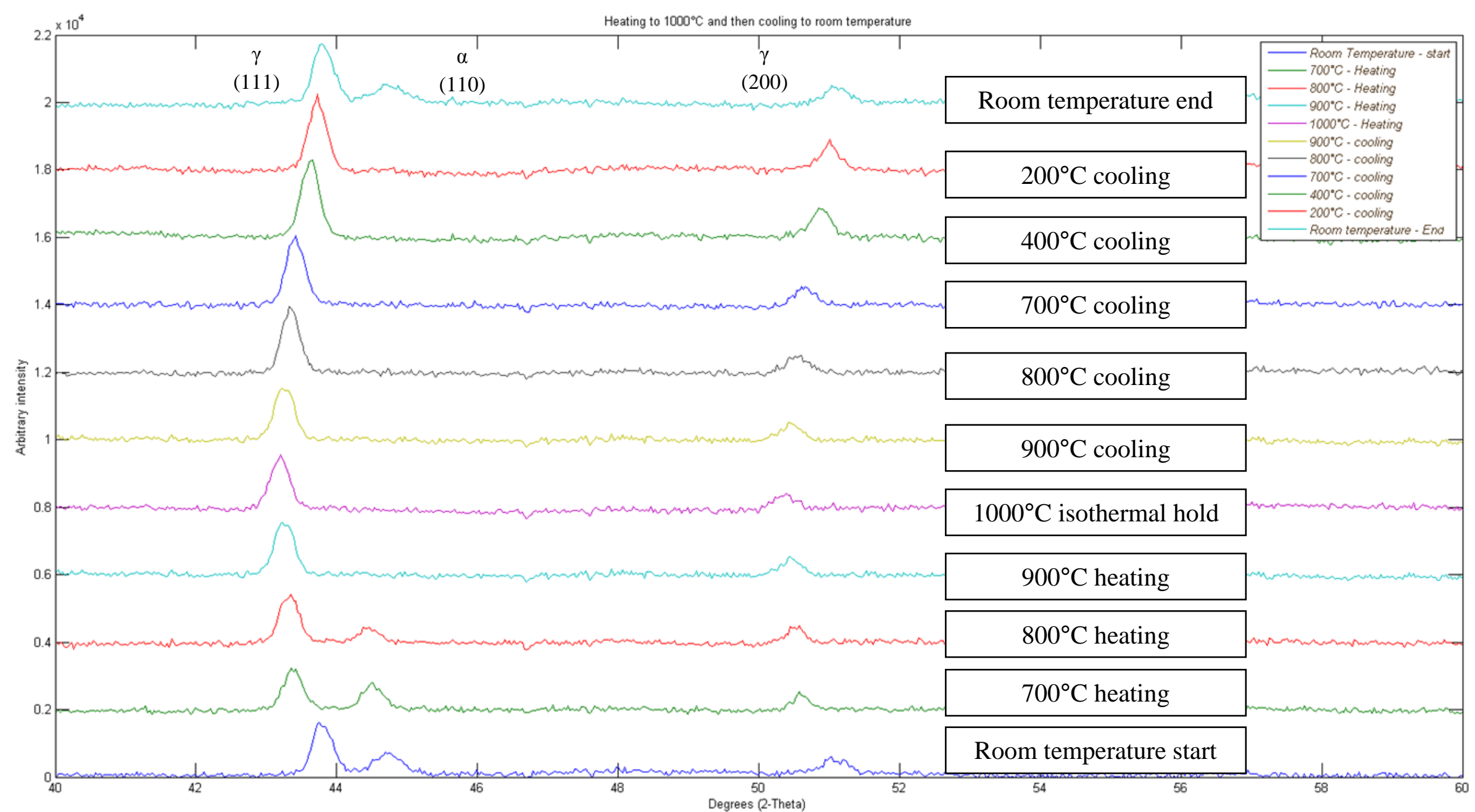

Figure 7: A series of XRD traces focused on the angles that contain the most intense FCC and BCC peaks. The traces have been offset by an arbitrary amount so the effect of increasing the temperature can be compared. 


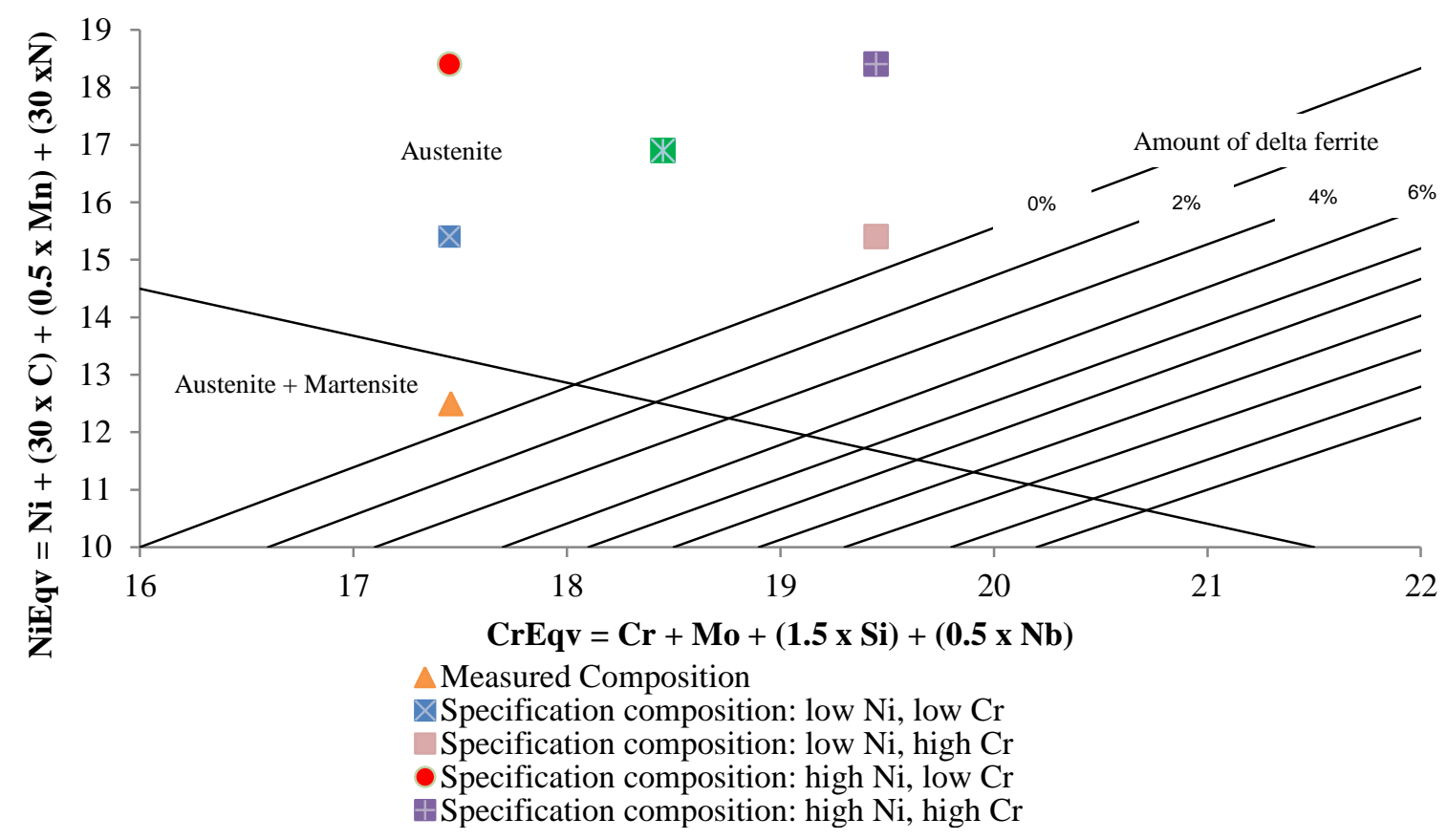

Figure 8: A digitized DeLong diagram [14] with data points plot using the nickel and chromium equivalents shown in the diagrams axis. It shows the measured composition of the steel and the effect of varying the nickel and chromium levels between the upper and lower limits of the ASTM specifications. The data points for the ASTM specification material [16] are in the austenite region of the DeLong diagram where as the measured composition is in the austenite + martensite region.

The DeLong diagram is a useful tool for predicting the non-equilibrium phase composition of weldments [14], it is of interest to know what phases are predicted for the composition of the as-received material. Figure 8 shows a DeLong diagram with several data points plot on it. The data point for the measured composition lies in the austenite + martensite region which is consistent to the microstructural analysis shown in Figure 1. The data points shown for the ASTM specification material were varied between the upper and lower limits for the nickel and chromium content. It was found that the specification materials was predicted to have an austenite microstructure, and while varying the chromium and nickel content did have an effect on the chromium and nickel equivalents it was not enough to change the predicted microstructure into another phase field. The specification composition data points in Figure 8 were taken with the nitrogen and carbon content at the maximum values allowed.

To examine the effect the carbon and nitrogen content has on the stability of austenite the measured composition of the steel was used for all elements except nitrogen and carbon and the nitrogen and carbon levels were varied between zero and the upper ASTM specification [16]. The resulting effect on the chromium and nickel equivalents is shown in Figures 9 (a) when varying the $\mathrm{N}$ content and Figure 9 (b) when varying the carbon content. It can be seen 
that nitrogen has the largest effect due to the low measured nitrogen content in the steel, while the measured carbon content was fairly near the upper limit of the ASTM specification.

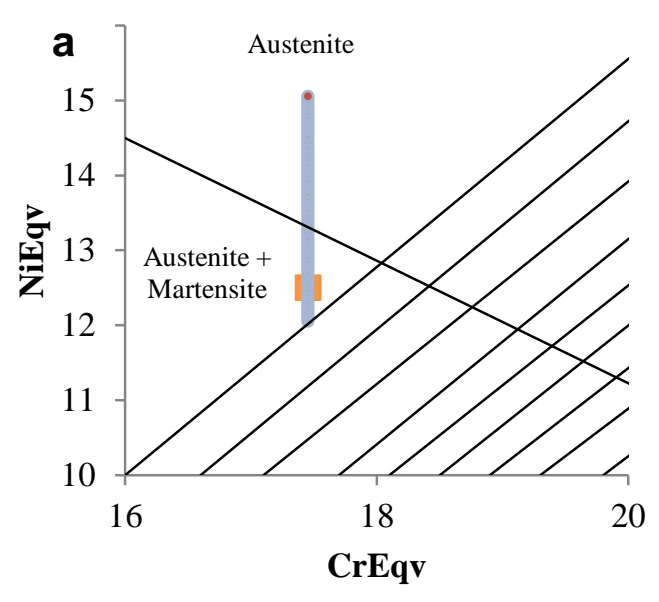

Measured Composition - Varying N

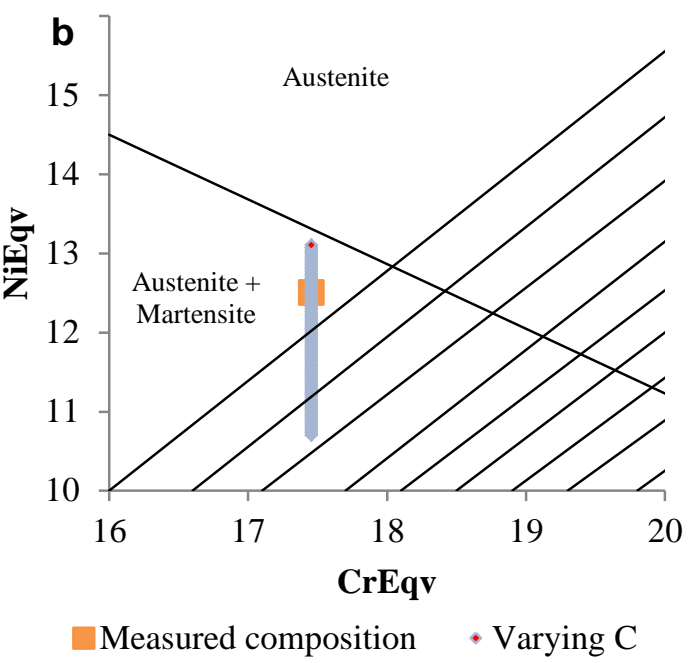

Figure 9: (a) This DeLong diagram shows the measured composition while varying the nitrogen content from 0 to the upper limit of the ASTM specification. (b) This DeLong diagram has a plot of the measured composition while varying the carbon content from 0 to the upper limit of the ASTM specification.

\section{Effect of thermal ageing}

This material has been used in other work to quantify the size of the sigma phase particles where it was noticed that the amount of ferrite increased as sigma phase formed [6]. Figure 10 (a) shows an EBSD phase map of the 321 grade stainless steel after ageing at $750^{\circ} \mathrm{C}$ for 12562 hours. The sigma phase particles can be identified by EDS as they have a high chromium content, and with EBSD with a tetragonal crystal structure. This EBSD map was collected simultaneously with EDS data and the constructed chemical maps are shown in Figure 10 (b-g). The EDS maps show a high chromium content of the sigma phase compared to the matrix phases, but it is also interesting to note that there is an increased nitrogen content in the sigma phase. As nitrogen is known to be a strong austenite stabiliser the increased nitrogen content in sigma phase could possibly be a reason for the increase in ferrite content as the nitrogen is removed from solid solution the austenite becomes less stable and transforms to ferrite with increased ageing time. The presence of nitrogen is also prevalent in the titanium carbo-nitrides but these were not found to increase in volume fraction with thermal ageing unlike the sigma phase. As many power plant components are 
made with tight dimensional tolerances, the expansion of components during thermal cycling caused by the transformation of austenite to ferrite has the potential to bring the components out of specification.

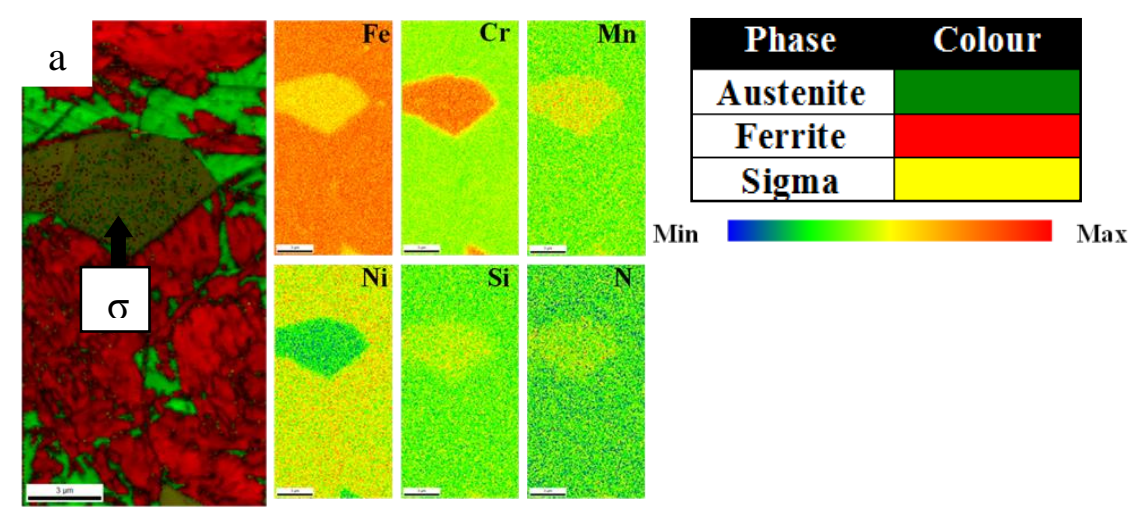

Figure 10: Combined EBSD and EDS maps showing austenite, ferrite and sigma phase. The images are (a) a phase map (b-g) EDS chemical intensity maps.

\section{Conclusions}

The initial microstructure of the 321 stainless steel showed an unusual microstructure with regions of up to $50 \%$ ferrite, a small amount of titanium carbo-nitrides with the remainder being austenite. The thermodynamic calculations run from the composition of the as-received material showed that the standard heat treatments should be successful at dissolving all phases leaving only austenite. After a heat treatment at $1050^{\circ} \mathrm{C}$ for 90 minutes, no change in microstructure was observed in the cooled sample. The dilatometer data from the isothermal hold at $1150^{\circ} \mathrm{C}$ then cooling at a rate of $500^{\circ} \mathrm{Cs}^{-1}$ showed no noticeable transformation during heating but did show a small peak around $100^{\circ} \mathrm{C}$ while cooling. The XRD experiments show the presence of ferrite at room temperature which is then completely dissolved at $900^{\circ} \mathrm{C}$ but forms again when cooling below $200^{\circ} \mathrm{C}$. The XRD results confirmed by the dilatometer data indicates that a displacive transformation is occurring below $200^{\circ} \mathrm{C}$. Melting a sample in a vacuum and cooling quickly had the effect of increasing the amount of ferrite, while melting the sample in a nitrogen containing atmosphere had the effect of completely removing the ferrite. This indicated that the formation of ferrite appears to be a result of composition rather than a function of cooling rate. Thermodynamic predictions performed in Thermocalc predict a significant ferrite content at room temperature at equilibrium and the DeLong diagrams predict an austenite + ferrite microstructure. Altering the nitrogen content between a zero value and the maximum value show a significant effect on the DeLong diagram. 
Sigma phase formed during thermal ageing, the EDS maps indicated that there was an enrichment of nitrogen in the sigma phase particles. This increased nitrogen content in the sigma phase causes a reduction of nitrogen around the particle which may be one of the causes of the increased ferrite content, especially in the regions around the particles. The transformation of austenite to ferrite is known to be accompanied by an increase in volume which is of relevance to components made with tight dimensional tolerances.

\section{Acknowledgements}

The authors would like to thank EDF Energy and Loughborough University for providing the funding and the materials for this project.

\section{References}

[1] W.J. Mills, Eng. Fract. Mech., 1988, 30,469-492

[2] A.S. Grot, J.E. Spruiell, Metall. Matter. Trans. A, 1975, 6A,2023-2030

[3] ASTM 249/A249M - 10a, ASTM, West Conshohocken, PA, USA

[4] M. Grosse, D. Kalkhof, M. Niffenegger, L. Keller, Matter. Sci. Eng. A, 2006, A437, 109113

[5] K. Liu, Z. Zhao, Z. Zhang, J. Matter. Eng. Perform., 2012, 21, 1772-1776

[6] H.C Fiedler, B.L. Averbach, M.Cohen, Trans. Amer. Soc. Metals, 1954, 47, 267-290

[7] A. Das, P.C. Charkraborti, S. Tarafder, H.K.D.H Bhadeshia, MST, 2011, 27, 366-370

[8] R.P. Reed, Acta Metall Mater, 1962, 10, 856-877

[9] J.H. Lee, T. Fukuda, T. Kakeshita, Japan Institure of Metals, 2009, 50, 473-478

[10] Green, G, Higginson, R, Hogg, S, Spindler, S, Hamm, C Mater. Sci. Technol. 2014 30(12), 1392-1398

[11] C.L. Magee, R.G. Davies, Acta Metall. Mater., 1972, 20, 1031-1043

[12] J. Erneman, M. Schwind, L. Nylöf, J. Nilsson, H. Andrén, J. Ågren, Metall. Matter. Trans. A, 2005, 36, 2595-2600

[13] A.L. Schaeffler, Met. Prog., 1949, 56, 680-688

[14] W.T. Delong, Met. Prog, 1960, 77, 98

[15] R.P. Reed, JOM, 1989, 41,16-21

[16] ASTM A778 - 01(2009)e1, ASTM, West Conshohocken, PA, USA 